\title{
An Empirical Analysis of the Abuse-of-Power Crime
}

\author{
Wuwei Zhang ${ }^{1}$ \\ ${ }^{1}$ Chuxiong Normal University, \\ Chuxiong, Yunnan, China \\ Hongli Peng ${ }^{1}$ \\ ${ }^{1}$ Chuxiong Normal University, \\ Chuxiong, Yunnan, China
}

\author{
Guiping $\mathrm{Li}^{1}$ \\ ${ }^{1}$ Chuxiong Normal University, \\ Chuxiong, Yunnan, China \\ Mingwu Zhou ${ }^{1}$ \\ ${ }^{1}$ Chuxiong Normal University, \\ Chuxiong, Yunnan, China
}

\begin{abstract}
We use the data of legal cases involving the abuse-ofpower crime in recent 30 years to conduct positive analysis, based on this model and the analysis of the quantitative function. At last prop up with suggestion to check the occurrence of crime of post.
\end{abstract}

Keywords: An empirical analysis crime

\section{INTRODUCTION}

\subsection{The complete information static game of the agent and the principal}

Because of the rent in the market, if the agent accepts bribery he commits the abuse-of-power crime. For firms, rent seeking activity makes the resource allocation of enterprises inefficient, and reduces the profit of firms and the revenue of principals. For countries, the rent seeking activity would help officials to embezzle the "rent" that belongs to the nation, augmenting the unjust income distribution and thus decreases social welfare. The shareholders and national government, acting as principal, would try to prevent the rent seeking activity. The most fundamental method to do this is to eliminate the rent itself. But it is impossible to do so because of the existence of both the market failure and government, the fundamental measure is to undertake economic and political reform and reduce administrative interference so as to abate the rent to its minimum level. The reform complex carried out by the new cabinet in China is aiming at solving this problem. In circumstances where the rent cannot be eliminated, a more feasible strategy for the principal to prevent the abuse-ofpower crimes is to check the behavior of the agent, and reduce the expected profit of rent seeking by busting the cost through punishment on power abusing.

Suppose that in a market there are one principal and one agent, if the principal do not investigate and prosecute the agent and the agent do not commit crime, the payoff of them are $\mathrm{V}$ and $\mathrm{W}$ respectively. The cost of investigating and prosecution is $\mathrm{C}$, if the agent commits crime the principal would suffer from a loss of $\Delta \mathrm{V}$, but the agent can retrieve benefit of $\mathrm{k}_{0} \Delta \mathrm{V}$. But if this crime is investigated and prosecuted by the principal, the agent has to pay $\mathrm{k}_{1} \Delta \mathrm{V}$ as the price, the rent seeker has to pay $k_{2} \Delta \mathrm{V}$. The agent's strategy choice is abuse the power or not, the principal's strategy choice is investigate or not. The payoff matrix is as follows:

Tab 1.game of one principal and one agent

\begin{tabular}{|c|c|c|c|}
\hline player & $\begin{array}{c}\text { strateg } \\
\mathrm{y}\end{array}$ & $\begin{array}{l}\text { Payoff of } \\
\quad \mathrm{A}_{1} \\
\mathrm{H}_{\mathrm{A}}\left(\mathrm{S}_{1} X\right. \\
\left.\mathrm{S}_{2}\right)\end{array}$ & $\begin{array}{c}\text { Payoff of } \\
\mathrm{B}_{1} \\
\mathrm{H}_{\mathrm{B}}\left(\mathrm{S}_{1}\right. \\
\left.\chi \mathrm{S}_{2}\right)\end{array}$ \\
\hline $\begin{array}{c}\text { Principal } \\
\text { investigates } \\
\text { Agent abuses }\end{array}$ & $(1,1)$ & $\begin{array}{c}\mathrm{V}-\mathrm{C}-\triangle \\
\mathrm{V}+\mathrm{k}_{0} \triangle \mathrm{V}+ \\
\mathrm{k}_{1} \triangle \mathrm{V}+\mathrm{k}_{2} \\
\triangle \mathrm{V}\end{array}$ & $-\mathrm{k}_{1} \triangle \mathrm{V}$ \\
\hline $\begin{array}{c}\text { Principal } \\
\text { investigates } \\
\text { Agent do not abuse }\end{array}$ & $(1,0)$ & $\mathrm{V}-\mathrm{C}$ & W \\
\hline $\begin{array}{l}\text { Principal does not } \\
\text { investigate } \\
\text { Agent abuses }\end{array}$ & $(0,1)$ & $\mathrm{V}-\triangle \mathrm{V}$ & $\frac{\mathrm{W}+\mathrm{k}_{0} \triangle}{\mathrm{V}}$ \\
\hline $\begin{array}{c}\text { Principal do not } \\
\text { investigate } \\
\text { Agent do not abuse }\end{array}$ & $(0,0)$ & V & W \\
\hline
\end{tabular}

If the investigation cost $\mathrm{C}$ is big enough, the principal would choose not to investigate. If the punishment afforded by the agent $k_{2} \Delta \mathrm{V}$ is big enough, the agent would give up committing crime. In case of the principal investigating, the agent would give up committing crime when $\mathrm{W}>\mathrm{W}-\mathrm{k}_{1} \Delta \mathrm{V}$, and commit crime when $\mathrm{W}+\mathrm{k}_{0} \Delta \mathrm{V}>\mathrm{W}$, This reveals that it's necessary for the principal to investigate, and once the investigation and prosecution weakens, more crimes would be committed. 


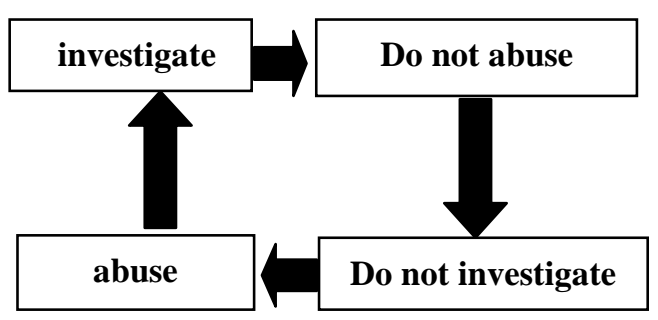

Fig 1. The principal-agent decision circulation

There exists no pure strategy nash equilibrium in this game. So we solve its mixed strategy equilibrium. Suppose the probability of the principal investigating is $p$ and the probability of the agent abusing is $\mathrm{q}$.

Epected payoff of the principal is $\mathrm{k}_{2} \triangle \mathrm{V}$

$$
\mathrm{EH}_{\mathrm{A}}=\mathrm{V}+\mathrm{pqC}-\mathrm{pC}-\mathrm{q} \triangle \mathrm{V}+\mathrm{pq} \mathrm{k}_{0} \triangle \mathrm{V}+\mathrm{pq} \mathrm{k}_{1} \triangle \mathrm{V}+\mathrm{pq}
$$

Expected payoff of the agent is

$\mathrm{EH}_{\mathrm{B}}=\mathrm{W}-\mathrm{pqW}+\mathrm{q} \mathrm{k}_{0} \triangle \mathrm{V}-\mathrm{pq} \mathrm{k}_{1} \triangle \mathrm{V}-\mathrm{pq} \mathrm{k}_{0} \triangle \mathrm{V}$

F.O.C

$$
\frac{\partial E H_{A}}{\partial q}=p C-\Delta V+p k_{0} \Delta V+p k_{1} \Delta V+p k_{2} \Delta V
$$$$
\frac{\partial E H_{A}}{\partial p}=q C-C+q k_{0} \Delta V+q k_{1} \Delta V+q k_{2} \Delta V
$$$$
\frac{\partial E H_{A}}{\partial p}=0, \quad \frac{\partial E H_{A}}{\partial q}=0
$$$$
p *=\frac{1}{\frac{C}{\Delta V}+\mathrm{k}_{0}+k_{1}+k_{2}},
$$$$
q *=\frac{1}{1+\left(k_{0}+k_{1}+k_{2}\right) \frac{\Delta V}{C}}
$$

The size of $\mathrm{p}^{*}$ is determined by various cost $\mathrm{C}$ devoted by the principal to investigate and prosecute, rent $\Delta \mathrm{V}$, the degree of rent seeking $\mathrm{k}_{0}$, the punishment coefficient for the agent $\mathrm{k}_{1}$ and $\mathrm{k}_{2}$

The higher the cost $\mathrm{C}$ is, the smaller the probability of investigation would be. The smaller the rent $\Delta \mathrm{V}$ is, the smaller the probability of investigation would be. The higher the degree of rent seeking $\mathrm{k}_{0}$, the smaller the probability of investigation would be. The bigger the punishment coefficient for the agent $\mathrm{k}_{1}$ and $\mathrm{k}_{2}$, the smaller the probability of investigation would be.

The size of $\mathrm{q}^{*}$ is determined by various $\cos \mathrm{C}$ devoted by the principal to investigate and prosecute, rent $\Delta \mathrm{V}$, the degree of rent seeking $\mathrm{k}_{0}$, the punishment coefficient for the agent $k_{1}$ and the punishment coefficient for the rent seeker $\mathrm{k}_{2}$.

The higher the cost $\mathrm{C}$ is, the smaller the probability of investigation would be. The smaller the rent $\Delta \mathrm{V}$ is, the bigger the probability of abusing would be. The higher the degree of rent seeking $\mathrm{k}_{0}$, the bigger the probability of abusing would be. The bigger the punishment coefficient for the agent $k_{1}$ and $k_{2}$, the bigger the probability of abusing would be.

\subsection{The function of the amount of the abuse-of-power crime}

There is connection between the revenue of committing crimes, the probability of getting caught, and the severity of punishment after conviction, the connection can be described using a function $O_{i}=O_{i}\left(g_{i}, p_{i}, \mathrm{f}_{i}, u_{i}\right)$

In Becker(1968)'s analysis, the income of commiting crime $\mathrm{g}_{\mathrm{i}}$ is not considered as a prime factor that influence the number of crimes. However, in terms of the abuse-ofpower crime, the increase of the revenue from commiting crimes would definitely lead to the rise the number of crimes. So we include this variable in the function.

\subsection{Analysis of the quantitative function of the abuse- of-power crime}

Based on Becker's analysis, The number of crimes is the function of the expected income of committing the crime $g_{i}$, the probability of getting investigated and prosecuted after committing crimes $p_{i}$, and the severity of punishment $\mathrm{f}_{i}$.

$$
\begin{gathered}
O_{g i}=\frac{\partial O_{i}}{\partial g_{i}}>0 \\
O_{p i}=\frac{\partial O_{i}}{\partial p_{i}}<0 \\
O_{f i}=\frac{\partial O_{i}}{\partial f_{i}}<0
\end{gathered}
$$

The number of crimes is positively correlated with the expected income of committing the crime $g_{i}$, and negatively correlated with the probability of getting investigated and prosecuted after committing crimes $p_{i}$, and the severity of punishment $\mathrm{f}_{i}$.

\section{Empirical evidence of the abuse-of-power crimes}

\subsection{The growth rate of the abuse-of-power crimes}

In the principal-agent decision circulation, the following circulation is more prevalent:

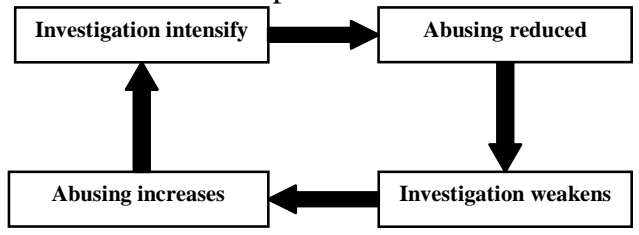

Fig2. the principle-agent decision circulation 2 
The growth rate of crimes and the number of criminals involved is as follows:

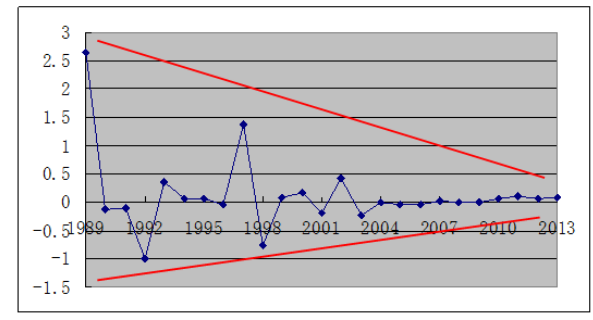

Fig 3. the growth rate of the abuse-of-power crimes prosecuted and convicted and number of criminal involved

The data in these years follow the cycle of the principalagent decision circulation revealed above. The data shows that since the People's prosecutor office intensified the investigation and prosecution of the abuse-of-power crimes, the growth rate of the number of crimes in the year 1990,1991 and 1992 is much lower than that of 1989 . The same story happened after 1993, the growth rate of the number of crimes in the year 1994,1995 and 1996 are smaller than that of 1993.and the same story occurs again and again in 1997, 2002, 2006, the growth rate in the year 2006 is $-3.39 \%$,lower than that of 2002. But in 2007 it rebounds to $1.78 \%$, and it jumped to $6.15 \%$ in $2010,6.36 \%$ in $2012,6.38 \%$ in 2013 .

If we look at the data of the growth rate of the number of convicted vice-provincial level officials(an indicator of high-level officials), we can find the above decision circulation stills rules the fact. After 3 officials of viceprovincial or above level were convicted in 1989, the growth rate of crimes committed by officials of this level fell below the 1989 level in the following 3 years. Since the year 1994 and 1995 have witnessed the conviction of 2 and 3 high level officials, no official of that level was convicted in 1996. The deterrence effect is quite manifest. Another example is the year 1997,when 5 high-level officials get convicted, the average growth rate of high-level official criminals fell a lot. Till 2002, the rate has slid to $28.6 \%$.However, the rate bounced back to $88 \%$ in the year 2003 , the same story again, after 9 high level officials get convicted, the growth rate fell sharply in the following years, down to $-23.1 \%$ in 2006 . In 2007 , this rate bounced back to $20 \%$, after getting 12 officials convicted, the rate dip down to $-58.3 \%$ in 2008 , but bounce back to $120 \%$ in 2009. After getting 11 officials convicted in that year, the growth rate fell again in the following 3 years and bounce back to $6.38 \%$ in 2013 . This is a cyclical pattern ruled by the principal-agent decision circulation.

In terms the Chuxiong prefecture in Yunnan province, the criminals of the abuse-of-power crimes have increased from 46 in 1997 to 129 in 2012, demonstrating the cyclical pattern together with the nationwide data. In 1999 the growth rate of the abuse-of-power criminals increased to $24.5 \%$,after convicting 61 criminals, the following 3 years witness a much lower growth rate. But it jumped to $34.5 \%$, after convicting 78 people, the following 2 years witness the rapid fall of growth rate, marked by the $-40.9 \%$ in 2005 . While the rate jumped back to $36.5 \%$ in 2006 , but dip to $16.9 \%$ after convicting 71 criminals. The growth rate bounced back again in 2008 to $64.4 \%$, but fell sharply in the following 3 years after 97 people get convicted.

\subsection{The trend of growth rate}

From Fig3 we can find out that although the crimes and crimals growth rate(in terms the abuse-of-power crime) between 1989 and 2013 fluctuates violently, with the peak being $250 \%$ and the bottom being $-100 \%$, it demonstrates a very manifest downward trend.

Form Fig4 it is easy to find out that although the crimes and crimals growth rate(in terms the abuse-of-power crime) of provincial or above level officials between 1989 and 2013 fluctuates violently, there is not a downward trend.

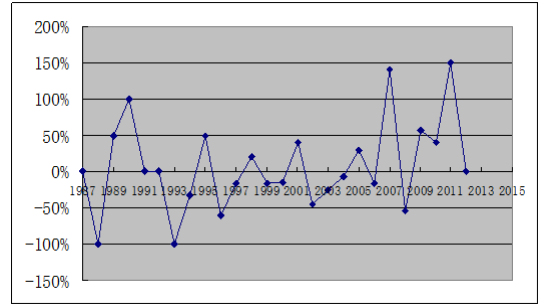

Fig4. the growth rate of the abuse-of-power crimes committed by officials of provincial or above level

Fig5 shows that the peak of crime and criminal growth rate(in terms the abuse-of-power crime) of Chuxiong is $64.41 \%$ and the bottom is $-40.91 \%$. the fluctuation is not so fierce as the nationwide picture, but there is no downward trend.

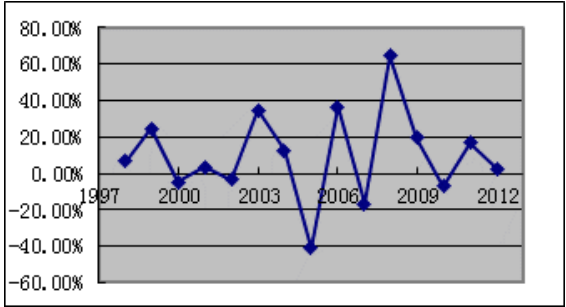

Fig5. The growth rate of criminals convicted of the abuse-of-power crime in Chuxiong prefecture 


\begin{tabular}{|c|c|c|c|c|c|c|}
\hline \multirow{2}{*}{} & \multicolumn{2}{|c|}{ Before 2000 } & \multicolumn{2}{c|}{$2001-2005$} & \multicolumn{2}{c|}{$2006-2013$} \\
\cline { 2 - 7 } & peak & $\begin{array}{c}\text { botto } \\
\mathrm{m}\end{array}$ & peak & bottom & Peak & $\begin{array}{c}\text { Botto } \\
\mathrm{m}\end{array}$ \\
\hline $\begin{array}{c}\text { Nation } \\
\text { wide }\end{array}$ & $264 \%$ & $\begin{array}{c}- \\
100 \%\end{array}$ & $43 \%$ & $-24 \%$ & $10 \%$ & $-3 \%$ \\
\hline $\begin{array}{c}\text { Provin } \\
\text { cial or } \\
\text { above } \\
\text { level } \\
\text { Nation } \\
\text { wide }\end{array}$ & $100 \%$ & $-100 \%$ & $40 \%$ & $-44 \%$ & $150 \%$ & $-55 \%$ \\
\hline $\begin{array}{c}\text { Chuxio } \\
\text { ng }\end{array}$ & $24 \%$ & $-5 \%$ & $34 \%$ & $-41 \%$ & $64 \%$ & $-17 \%$ \\
\hline
\end{tabular}

Fig6. peaks and bottoms of the growth rate of the abuse-of-power crimes and criminals

\section{Conclusion}

(i)Increase the cost of committing crimes. The direct cost of bribery can be elevated by building more complete institutions, e.g. the monitoring mechanism and fiscal supervisory mechanism. Once there is more effective monitoring mechanism,corruption would become a lot more complicated than now. For example, it would take rent seekers more effort to bribe the agents. Besides that, disseminating the power is an effective approach to take precaution against the abuse-of-power crime. Because if the decisive power is surrogated by several agents, it is a lot more difficult for the rent seekers to control where things goes for him.

(ii)Reduce rent through further market. Rent arises in government interference to solve market failure problem, but the market failure in China, in many cases, is the product of incomplete transition towards market economy. So we can expect that the fundamental approach of reducing the rent is to further intensify market reform aiming at building more complete and robust market institutions, so that more resource can be allocated by the guide of market.

(iii)Improve the rate of arresting rate and, so as to the probability of getting punished once the agents commit crimes. This would effectively deter the potential criminals.

(iv)strengthen the punishment and penalty after conviction to lift the cost the committing crimes.

\section{Acknowledgments}

This paper supported by Science and Research fund project of Chuxiong Normal University (10YJZD02, YJXSDTR06).

\section{References}

[1]. Dingding Wang, Economic analysis on corruption, Strategy and Management, 2000(6)

[2]. Fucai Dai, work report of the People's Prosecuting Office of Chuxiong, Chuxiong Daily, Feb $26^{\text {th }}, 2013$

[3]. Gary S. Becker, 1968. "Crime and Punishment: An Economic Approach," Journal of Political Economy, University of Chicago Press, vol. 76, pages 169.

[4]. Gary. S. Becker, The Economic Approach to Human Behavior, The University of Chicago Press, Sept. 1978

[5]. John F. Nash, Lloyd S. Shapley, John C. Harsanyi, Reinhard Selten, Robert J . Aumann, Harold W. Kuhn, Classics in Game Theory Publishing House of Renmin University of China, Jan.2013

[6]. http://news. QQ. com 